\title{
Instantáneas: la lectura en los tiempos que corren
}

\section{Sorrentino, Florencia Lila}

Resumen:

La percepción actual de la fugacidad del tiempo incide en los modos de leer y escribir, en la forma de comunicarnos y en la circulación de la información. En este contexto, la literatura y, específicamente, la escritura de instantáneas conforman un género contemporáneo que tiene como propuesta el impacto a través de las palabras. Estos escritos establecen un diálogo con la fotografía ya que reproducen un momento que, como obras artísticas, exhiben imágenes (en palabras) otorgando multiplicidad de sentidos. En el siguiente ensayo reconoceremos algunas de las características de este nuevo género a partir del análisis de diferentes obras

Cuadernos del Centro de Estudios de Diseño y Comunicación №72

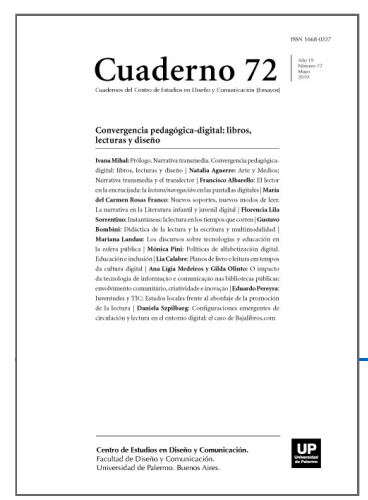

ISSN: 1668-0227

Convergencia

pedagógica-digital:

libros, lecturas y

diseño

Año XIX, Mayo 2019, Buenos Aires, Argentina | 194 páginas

descargar PDF ver índice de la publicación

Ver todos los libros de la publicación

compartir en Facebook

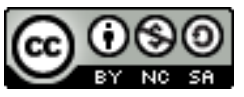
Esta obra está bajo una Licencia Creative Commons Atribución-NoComercialCompartirlgual 4.0 Internacional de autoras argentinas como Silvia Molloy, Mariana Enriquez y Selva Almada.

Palabras clave: Instantáneas - Literatura - Virtualidad - Lectura - Escritura.

$\left(^{*}\right)$ Especialista docente de nivel superior en Educación y TIC, y en educación en contextos de encierro. Profesora y licenciada en Letras (UBA). Adscripta a la Didáctica Especial y Prácticas de la Enseñanza en Letras (UBA) e investigadora del Proyecto UBACyT de la cátedra. Desarrolla diferentes investigaciones coordinadas por el Dr. Gustavo Bombini y por Mg. Mirta Gloria Fernández y ha publicado diferentes trabajos sobre estas áreas específicas. Actualmente, trabaja como docente en escuelas secundarias del partido de Avellaneda y dicta seminarios y talleres en la UNDAV y la UNSAM.

Introducción

En el Siglo XXI, en la era digital, en un mundo globalizado...continuamos leyendo. El libro no ha muerto y la lectura, tampoco. Es más, en nuestra vida diaria hay más letras escritas que abrazos. Estamos en constante comunicación vía Facebook, Twitter, Whatsapp, entre otras formas de contacto interpersonal. Y así, las maneras de comunicación actuales reemplazan (o completan) las anteriores pasando de lo analógico a lo digital 
(Cassany, 2000), de las extensas cartas amorosas a un simple emoticón con forma de corazón. Esto nos indica, entre otras cosas, que nos "falta tiempo" y el bombardeo publicitario que promueven diferentes empresas saca su ventaja de esta situación: cómo estar activos o qué debemos consumir para estar con un mejor aspecto a pesar del trajín diario, nos recuerda que estamos sobreexigidos. En este sentido, la falta de tiempo y el consumo de la publicidad -que nos convence de que esto es así- producen un estado de aceleración constante y/o la búsqueda de actividades por demasía. Por lo tanto, en el ámbito de la literatura es esperable que los lectores no disfruten de sus libros sentados en un sillón en la tranquilidad de la tarde como sella el ideal romántico del siglo XIX sino que, es más probable, que lean con los últimos suspiros de la noche haciendo grandes esfuerzos -0 aprovechando el insomnio producido por los efectos de esta nueva era-. Otra opción posible es leer en un dispositivo electrónico durante los "momentos libres" del día. Esto significa, mirar una pantalla mientras almorzamos -obviando, las relaciones cara a cara- o durante el trayecto en los traslados diarios. Los hábitos han cambiado por las diferentes transformaciones económicas, políticas, sociales y culturales que se viven a nivel global. Entonces, o leemos lo mismo en forma fragmentaria o la literatura se mimetiza con el contexto y trabaja en una producción de obras en las cuales se exprese la fugacidad de los tiempos que corren. La literatura argentina, a lo largo de la historia, siempre tomó una postura frente al contexto político y social en el cual se enmarcaba. En este sentido, si bien podemos encontrar en el recorte de textos realizado, escritos que abordan cierta crítica social, reflexionaremos en el formato de los mismos, en sus características, en su brevedad para luego analizar su conformación textual que parte de la representación de la realidad cotidiana de sus personajes, de los escritos autobiográficos y el recuerdo.

El concepto instantánea surge en la actualidad en algunas publicaciones en formato libro o digital y, en el ámbito académico, por ejemplo, como parte del programa del Taller de escritura de la profesora Alcira Bas en la licenciatura en comunicación audiovisual de la Universidad Nacional de San Martín. La intención es poder definir este género que surge como novedad y analizar algunas de sus expresiones artísticas ya que aparece como una necesidad emergente frente al poder de una realidad avasallante como es el de la aparición de las instantáneas en las redes sociales y hasta en libros publicados en la Argentina, traducidos a diferentes idiomas y difundidos en diferentes partes del mundo.

Este tipo de escritura nace entonces atendiendo a las formas de comunicación actuales y, por lo tanto, realizaremos un análisis de ciertas características de los medios en que estos textos circulan; es decir, veremos cómo las redes sociales se vinculan con la conformación de los mismos. En este sentido, analizaremos la "reedición" actual de los escritos de Julio Cortázar resignificando, a través de las redes sociales -y de la brevedad necesaria y obligatoria en Twitter-, al ya clásico argentino. Por otra parte, conformamos un corpus de lecturas de autoras argentinas que responden a las formas literarias que nos proponemos abordar y que fueron publicadas -en formato libro- durante los últimos años. El recorte engloba El desapego es una manera de querernos de Selva Almada, Las cosas que perdimos en el fuego de Mariana Enriquez y Varia imaginación de Sylvia Molloy; analizaremos en parte estos textos que nos mostrarán la conformación y las características propias del género instantánea.

Definiciones sobre el género

Las instantáneas aparecen profusamente hacia los años '90 en la Argentina. La generación de jóvenes escritores comienza a retratar la realidad espasmódica de nuestro país y para lograrlo, moldean los géneros líricos y narrativos. En este trabajo nos centramos en la escritura de relatos breves los cuales conforman 
espacios en muchos libros de cuentos publicados en la actualidad. Con un afán investigativo podemos encontrar algunas definiciones -atisbos de ellas- sobre las características de este híbrido que nos proponemos definir y analizar en este trabajo. En la literatura francesa encontramos, a su vez, la publicación de Diario de Afuera de Annie Ernaux (1993) quien en su prólogo evidencia esta forma de escritura. Allí la autora se propone:

(...) alcanzar la realidad de una época -esa sensación aguda de modernidad que se tiene en una ciudad nueva sin poder definirla- a través de una colección de instantáneas de la vida cotidiana colectiva (...). Busqué practicar una suerte de escritura fotográfica de la realidad en la que las existencias cruzadas conservasen su opacidad y su enigma. (Ernaux, 1993, pp. 8-9)

Ernaux, no sólo se propone una narrativa breve sino que además retoma la propuesta de una escritura realista, vigente en la literatura actual, pero fundamentalmente, aborda intencionalmente el auge de la escritura autobiográfica, de la expresión de lo íntimo en la literatura, y hace un juego deliberado entre el diario íntimo y, en este caso, de afuera. Esta escritura, este show de la intimidad, según afirma Paula Sibilia (2008), lo podemos observar en las diferentes formas de comunicación actuales: en las redes sociales, en los medios de comunicación virtuales y hasta en la televisión a partir de los programas de chimentos o en su expresión máxima: los reality shows. Entonces, en las diversas formas de comunicación virtual, en los blogs o en Facebook, se nos representan las expresiones de la intimidad que se emparentan con los géneros autobiográficos más clásicos. El yo que se representa en la web suele ser triple: es al mismo tiempo, autor, narrador y personaje. Sin embargo, la mayor diferencia entre las autobiografías más clásicas y las actuales es la extensión. Es por eso que ya no se las escribe en grandes tomos sino que se elige otras formas de expresión. Anne Marie Chartier (2009) en una entrevista expresa:

(...) la cuestión es saber si la lectura del texto está condenada a convertirse en un modo de información anexada a las industrias de la imagen y el sonido o si existe todavía un futuro significativo para los saberes construidos en la sola escritura, sin ninguna imagen. Cuanto más habituados estamos a leer textos escritos combinados con imágenes, más difícil parece prescindir de ellos. La cultura del siglo XX, ya sea la literatura, la filosofía, las ciencias sociales, pero también la cultura política, médica, jurídica, estaba constituida por el discurso escrito. Las generaciones venideras ¿tendrán la curiosidad y la paciencia de leer todavía La Crítica a la Razón Pura de Kant o En búsqueda del Tiempo Perdido de Marcel Proust? (Chartier, 2009, s/n)

Por supuesto que en estas formas de comunicación los lenguajes audiovisuales cobran un lugar preponderante a la hora de elegir lecturas, comprender realidades y exteriorizar estados. Sin embargo, la cultura escrita no desaparece sino que se combina con otras formas de expresión. Igualmente, y teniendo como fundamento la divulgación de los textos eleccionados y del género instantánea, el texto no necesita de la imagen pero ingeniosa y artísticamente transforma, de manera metafórica, en imagen sus textos.

La selección realizada, conforma una serie que contiene las características de la narración de un recuerdo. A partir de entrevistas realizadas a las escritoras nos anoticiamos que son momentos vividos por ellas en los años de su niñez o adolescencia. En este sentido reafirmamos lo propuesto sobre la expansión actual de un cierto tipo de texto autobiográfico a partir de la proliferación de diferentes plataformas en las que podemos compartir lo que nos pasa: “¿Qué estás pensando?” en Facebook nos abre la puerta para expresar nuestra intimidad -y para observar la del resto- al igual que sucede en otras redes sociales. En este sentido, es importante destacar que las instantáneas son predominantemente realistas. Ellas hacen alusión a la cotidianeidad de los personajes, a un 
momento en la vida de ellos, no el más extraño ni el más singular sino aquél que adquiera múltiples significados para la conformación del yo y de la autobiografía como género.

Las instantáneas son textos fugaces pero increíblemente potentes. La brevedad es su característica y tal rasgo es el resultado de una serie de recortes históricos en los textos literarios. La primera gran transformación fue de la novela al cuento. Walter Benjamin observa, a principios del Siglo XX, el avasallamiento de la obra artesanal (la cual implicaba mucho tiempo para su creación) por la producción en serie y -retomando a Paul Valéryreafirma que el hombre contemporáneo ya no trabaja en lo que no es abreviable. Y explica:

De hecho, ha logrado incluso abreviar la narración. Hemos asistido al surgimiento del "short story" que, apartado de la tradición oral, ya no permite la superposición de las capas finísimas y translúcidas, constituyentes de la imagen más acertada del modo y manera en que la narración perfecta emerge de la estratificación de múltiples versiones sucesivas. (Benjamin, 1936, p. 7)

Entonces, si transitamos el paso de la novela al cuento, actualmente asistimos a una nueva transformación ya que los textos, aunque en libros de cuentos, son aún más breves o el recorte que en ellos se narra es aún más fugaz.

Las instantáneas se reúnen en serie que, como la colección de entradas en un blog, entrelazan un mismo tema, un mismo personaje, un mismo narrador. Paula Sibilia en La intimidad como espectáculo (2008) reflexiona sobre la exteriorización de la intimidad en el tiempo actual y gran parte de su análisis se basa en comprender la forma de comunicación en la cual esto se representa. En este sentido, hace alusión a la confección de blogs que si bien actualmente han sido reemplazados en su uso por diferentes redes sociales propone un análisis que emparenta entonces al blog con la serie de instantáneas. Así dice Sibilia:

[Los blogs] exhiben una serie de fotos fijas y bien ordenadas, retazos de instantes pegados uno después de otro: retratos instantáneos de momentos presentes de la propia vida que van pasando, pero que no se articulan y sedimentan para construir un pasado a la vieja usanza. En fin, una colección de Pompeyas petrificadas y primorosamente clasificadas en orden cronológico; nada de Romas eternas, infinitas y fatalmente desordenadas en una estructura narrativa con sueños de coherencia y vocación totalizadora. (Sibilia, 2008, p. 161)

Paula Sibilia recupera ciertas apreciaciones de Sigmund Freud en cuanto a los modos de inscripción en el pasado de la psiquis con las metáforas de Roma y Pompeya. Roma es la duración, la narración detallada, las novelas largas o las autobiografías en tomos y Pompeya es un tiempo de captura, corte, instante pero totalizante (Sibilia, 2008, p. 136) que, en el marco de este trabajo, configura a las instantáneas. Estos textos son como las entradas de los blogs los cuales establecen una relación coherente pero fragmentaria.

Estos escritos breves han comenzado a circular profusamente en la actualidad: Selva Almada y Mariana Enriquez, entre otras/os autoras/os jóvenes argentinas/os traducidas/os a diferentes idiomas proponen esta narrativa (no de manera excluyente). La instantánea es un híbrido que se caracteriza por la brevedad coincidentemente con el microrrelato pero se distingue del mismo ya que estos textos se agrupan aportando otros significados. Además, una instantánea puede estar compuesta por unos párrafos o por varias carillas con múltiples silencios característica que también imprime un sello único. No se restringe por las líneas que escribe (aunque, por supuesto, son textos breves) sino por la imagen que recorta. Como ejemplo, podemos analizar una 
serie de instantáneas de Selva Almada publicadas en El desapego es una manera de querernos (2015) en donde reúne diferentes relatos que se agrupan en serie. Allí, "Niños", "Chicas lindas" y "En familia" conforman grupos de instantáneas. Para este trabajo nos detendremos en la primera serie. Así aparece la instantánea inicial:

1. Niño Valor nació diez días después que yo, en el mismo hospital. Lo nombraron como me hubiesen nombrado de haber sido varón. Lo vistieron con la ropa celeste que mi madre había tejido para mí.

Su madre y la mía son hermanas.

Para jugar, nos vestían iguales y les decían a los desconocidos que éramos gemelos. Para seguir jugando, nos cambiaban la ropa y les decían a los conocidos que él era yo y que yo era él. (Almada, 2015, p 11)

Todas las instantáneas pueden ser leídas sueltas pero la lectura de todas, otorga otros significados. En esta podemos leer una autobiografía actual que no busca recuperar toda una vida en detalles sino el detalle de una vida que nos dará los indicios para saber sobre aquella que narra su relato: ese narradora-autora-personaje. Su nacimiento, la relación íntima con su primo y su mirada incómoda frente a su corporeidad y su condición de niña son los temas que aborda en estas pocas líneas. En este caso es un relato autobiográfico pero la operación puede ser la misma en otras instantáneas que presentan personajes a la manera de "falsas autobiografías". Lo significativo es la brevedad, el recorte, el detalle, la especificidad del fragmento en oposición a las características generales o las explicaciones. En la segunda de la serie también aparece Niño Valor, personaje que estable el hilo conductor en el grupo de instantáneas "Niños". En esta se relata un velorio y cómo ello impacta en la mirada de la niña que observa. Es un texto de ocho carillas que nos ayuda a reflexionar en las características del género instantánea. En la teoría de la narración se hace la diferenciación entre el tiempo de la historia y el tiempo del relato y, por lo tanto, un instante del tiempo de la historia en el relato, puede ocupar muchas líneas. En este sentido Gerard Genette (1989) establece el análisis de las dimensiones temporales y se detiene en las particularidades del relato moroso el cual posee pausas descriptivas y/o escenas. Es, por supuesto, el caso de la segunda instantánea de "Niños". Los silencios entrelazan series que, en el caso de la segunda instantánea, dependen unas a otras. Por otra parte, la serie que conforma el relato número 13 nos cuenta -y nos hace sentirla matanza de un chancho en el espacio del campo siempre desde la mirada -el focalizador- de la niña. Siete carillas, nueve blancos, diez instantáneas logran transmitir qué significa matar a un animal en el ámbito rural y qué significado tuvo para la niña. Reproducimos una instantánea que, entre silencios, ejemplifica la idea de este género como una imagen: "La sangre salía a chorros como si la mano invisible de un mago invisible fuese sacando pañuelos de seda roja anudados por aquel tajo oscuro, sin fin" (Almada, 2015, p. 58). La cotidianeidad del campo: criar, engordar y luego carnear un lechón se volvió un objeto literario que, además, es increíblemente potente. Pero, para lograrlo, trabaja con la metáfora, la mezcla entre realismo crudo y objeto lírico. Este contraste se realiza también en la segunda de las instantáneas mencionadas: asistir a un velorio pasa a tener un valor literario otorgado, por supuesto, por la autora. En el relato 13 aparece otra instantánea que nos muestra el desenlace del animal:

Peludo tenía ojos grandes, oscuros y húmedos. Tal vez se parecían a los ojos de las vacas, pero estos no eran de mirar lejos, de ver pasar trenes y camiones detrás del alambrado; no tenían el brillo melancólico del iris bovino. Estos eran ojos vivaces, de mirar cerquita, de acechar manjar entre la basura. 
Cómo eran de lindos los ojos de Peludo: dos gotas espesas de café entre su pelambre color té.

Muerto, dos piedras negras lisas. (Almada, 2015, p. 61)

Para el focalizador -la niña- el chancho había sido "Peludo", representando en este sustantivo propio la carga emocional puesta sobre el animal -y sobre los animales que en el campo sirven como alimento-. Un instante, un momento particular entre muchos momentos similares en los recuerdos de la autora conforman claramente la instantánea. El trabajo con lo visual: los ojos de Peludo, la apreciación desde la posición del focalizador y la diferenciación entre la vida y la muerte a través de las metáforas acerca de los ojos del animal. Muchas de las instantáneas, como dijimos, trabajan con el recuerdo. Allí el sujeto de la enunciación rememora y posiciona su mirada en un lugar y un momento anterior. Hay un presente narrado en las instantáneas que no trabaja (como puede suceder en el cuento) con idas y vueltas en la temporalidad de la historia ya que, fundamentalmente, recorta imágenes. Ese presente en la narración -la escena recordada- hace alusión a la percepción actual del tiempo. Paula Sibilia (2008) en su texto recurre a la idea de un presente constantemente presentificado, un presente perpetuo, una destemporalización que refiere a:

(...) un abandono de la idea del tiempo como flujo lineal y constante (...). Pero en la posmodernidad ese flujo se habría detenido, y la primera consecuencia de ese congelamiento sería un aparente bloqueo del futuro: ahora el porvenir no parece más hospedar aquella promisoria apertura hacia la diferencia. En cambio, se le teme a esa posibilidad que alberga en sí lo desconocido, por eso se intenta mantenerla técnicamente bajo control. Se desea la eterna permanencia de lo que es, una equivalencia casi total del futuro con el presente, un cuadro sólo perturbado por el feliz perfeccionamiento de la técnica. Como consecuencia el presente se volvería omnipresente, promoviendo la sensación de que vivimos en una especie de presente inflado. (Sibilia, 2008, p. 133)

En el texto literario, se narra ese presente con recursos estilísticos que sólo buscan posicionarnos en la escena, comprender esa realidad sin detenernos en otro punto temporal. La instantánea, además, no necesariamente presenta un conflicto en comparación los cuentos más clásicos y sus preceptos. Son relatos breves, simplemente imágenes transformadas en discurso escrito. $Y$ una serie de instantáneas es un conjunto de momentos potentes que establecen la continuidad a través de un hilo conductor o una enumeración. Julio Cortázar en "Algunos aspectos del cuento" describe a este género recurriendo al opuesto clásico: la novela; y establece la analogía: novela-cine y cuento-fotografía. En este punto, la instantánea toma del cuento -y del análisis de las características del mismo que hace Cortázar- una reflexión:

Los fotógrafos de la calidad de Cartier-Bresson o de un Basai definen su arte como una aparente paradoja: la de recortar un fragmento de la realidad, fijándole determinados límites, pero de manera tal que ese recorte actúe como una explosión que abre de par en par una realidad mucho más amplia, como una visión dinámica que trasciende espiritualmente el campo abarcado por la cámara. (Cortázar, 1970, p. 3)

Las instantáneas, son la expresión más actual y fiel a las palabras expresadas por Cortázar. Este género conforma fotografías en palabras incluso textos como imágenes. Precisamente, Cortázar también escribe una novela que no se desprende del concepto de explosión que propone sobre el cuento. Su novela, Rayuela, estableció rupturas en cuanto al canon literario que lo antecedía y estableció nuevas posibilidades de lectura: una lineal (intentando asir la completud y lo tradicional de las formas de lectura precedente) y otra, siguiendo el 
juego de saltos entre uno y otro capítulo buscando no sólo una historia sino reflexiones existencialistas y profundamente artísticas. En este sentido, hoy podemos leer Rayuela como un puñado de instantáneas. Este análisis se basa no sólo en las características y la propuesta lúdica e innovadora del autor sino que la era digital se ha apropiado de esta condición y hoy leemos Rayuela en 140 caracteres. ¿Una novela en pocas líneas? No, es la profundidad de muchos de los fragmentos de la obra que transforman la posibilidad de leer romas y pompeyas / cine o fotografía con la misma obra (sólo depende del momento y el formato que elige el lector). De esta manera se retoma el concepto propuesto en 1963 y además se imprime el sello actual. Se modifica la linealidad y el juego indicado para transformarlo en un texto multimodal y además, fugaz. @cortazario es uno de los usuarios más activos que comienza con frases extraídas de Rayuela para pasar a introducir otros textos del autor pero fundamentalmente, agrega fotografías, imágenes o GIF animados que desencadenan, a su vez, un usuario semejante en Instagram. Las estrategias, entonces, apelan a lo audiovisual y, además, muchas veces aparecen links a otros textos más extensos o, una estrategia posible, es la aparición de fragmentos a partir de las fotografías de libros impresos, una opción un tanto estafadora ya que en la foto hay muchos más que 140 caracteres. (Ver Figura 1)

En consonancia al género propuesto, cada instantánea cortazariana se vuelve autónoma, con un significado propio que puede adquirir otros cuando comenzamos a leer el conjunto de posteos en Twitter al igual que sucede en la serie de instantáneas.

Las redes sociales, la lectura en diferentes plataformas virtuales, por otra parte, problematizan la experiencia de la lectura y escritura como actos individuales. El posteo en cualquiera de las redes sociales admite un comentario, un emoticón positivo o negativo, y la difusión del escrito. Esto indica que el autor no está solo, quiere exteriorizar eso que escribe y, a la vez, hay un auditorio que operará sobre esto. En este marco, encontramos plataformas de escritura literaria como Wattpad1 en las cuales los lectores interactúan con el autor en el momento mismo de su producción y esto incide en los actos futuros de los personajes (Sorrentino, 2016). Las tecnologías comúnmente llamadas de la información y la comunicación son difusoras de textos literarios y productoras de otros muchos que aún estamos descubriendo. Desde los más jóvenes hasta los más grandes publican sus intereses, difunden sus escritos o promueven lecturas a través de reseñas, links o videos como sucede, por ejemplo, con la comunidad booktuber y su gran producción acerca de las obras publicadas. Los posteos literarios en diferentes plataformas realizan redes que conectan y, por supuesto, transforman la literatura.

En lo que respecta a la escritura de relatos breves, el libro de cuentos recientemente publicado por Mariana Enriquez, Las cosas que perdimos en el fuego (2016), tiene la particularidad de contar con tres series de instantáneas: "Los años intoxicados", "Verde rojo anaranjado" y "Las cosas que perdimos en el fuego". En la primera de ellas se narra las vivencias de una joven. Para hacerlo, titula cada una de las instantáneas con diferentes años significativos -autobiográficos- y consecutivos: desde 1989 hasta 1994 en los cuales hace alusión, como es de esperar, a la situación política de ese momento. Los relatos se conectan a partir de la tríada: mismas protagonistas y su relación afectuosa - relación con el contexto histórico - consumo de diferentes drogas. Los relatos funcionan como recuerdos de la narradora que hace una breve introducción para luego contar una escena específica, explosiva, sintética, como una fotografía que nos muestra "una realidad mucho más amplia". La primera de ellas inicia su relato situándonos rápidamente en ese tiempo y espacio: ese verano "se cortaba la electricidad en turnos de seis horas" para luego comentar la crisis económica que se vivía siempre desde una mirada adolescente- y explica que para ella y sus amigas esas cosas les parecían 
"estúpidas" y "ridículas". Luego de esa ubicación espacio-temporal se centra en el relato del viaje a toda velocidad en la caja de una camioneta para sentir la adrenalina, los golpes, la cercanía con las amigas. Como expresamos en un comienzo, la literatura siempre fue un lugar propicio para expresar verdades, críticas, puntos de vistas y palabras silenciadas en diferentes momentos históricos de nuestro país. Los años '90 fueron un momento de crisis, confusión, marginación y desempleo. Esta literatura fragmentaria nos muestra esa realidad y la mirada acerca del neoliberalismo- a partir de la selección de seis instantáneas de gran impacto, crudeza y denuncia pero, por sobre todo, se destaca la mirada de una adolescente en los años '90: "El presidente había tenido que entregar el mando antes del final de su período y a nadie le gustaba demasiado el nuevo aunque había ganado las elecciones por una mayoría impresionante" (Enriquez, 2016, p. 51) para luego detenerse fundamentalmente en la posibilidad novedosa de obtener un teléfono (de línea, por supuesto) para conversar horas con sus amigas.

Previamente a Enriquez, en el 2003 Silvia Molloy publica Varia imaginación en donde propone una serie de instantáneas reunidas por el título -y la temática- "Familia". Allí aparecen con diferentes títulos variados escritos autobiográficos de la autora. Uno de los textos, puede ser uno de los ejemplos más claros, puros y artísticos del género que aquí nos proponemos definir:

Plumetí, broderie, tafeta, falla, gro, sarga, piqué, paño lenci, casimir, fil a fil, brin, oraganza, organdí, voile, moletón, moleskin, piel de tiburón, cretona, bombasí, tobralco, terciopelo, soutache, cloqué, guipure, lanilla, raso, gasa, algodón mercerizado, bramante, linón, entredós, seda cruda, seda artificial, surah, poplin dos y dos, dri, loneta, batista, nansú, jersey, poplin, reps, lustrina, ñnadutí.

La exposición, La San Miguel de Elías Romero, La Saida. Los turcos de la calle Cabildo. Los saldos.

Canesú, rangland, manga japonesa, canottier, taller princesa, traje trotteur, pollera plissée, pollera tableada, pollera plato, pollera tubo, un tablón, una bocamanga, un pespunte, un añadido, una pinza, una pestillla, un hilván, las hombreras, ribetear, enhebrar, una pestaña, vainilla, punto yerba, un festón. La sisa, la hechura.

Recuerdo estas palabras de mi infancia, en tardes en que hacía los deberes y escuchaba hablar a mi madre y a mi tía que cosían en el cuarto contiguo. Reproduzco este desorden costurero en mi memoria. (Molloy, 2003, p. 21-22)

"Homenaje" (el título de esta instantánea) es una enumeración temática pero a la vez caó- tica de diferentes palabras que pertenecen al campo semántico de la costura, palabras que, como expresa el último párrafo, son el recuerdo de su infancia. Simplemente, una imagen auditiva, una serie de palabras que recrea en el lector una realidad, la cotidianeidad de la narradora-autora, una instantánea que representa a la vez, una totalidad: el ámbito en el que la niña pudo desarrollarse. Como vimos en Selva Almada, una acción repetida y rutinaria pero extraída de la memoria y transformada en un objeto sumamente literario. En este género los diálogos, muchas veces, son introducidos eliminando los guiones, como si pasaran a formar parte de la imagen a la vez que, disminuyen así la cantidad de líneas. El diálogo se enmarca, como en una fotografía, en la conformación de la estructura narrativa del párrafo en el cual se desarrolla el relato. En "Curas" de Sylvia Molloy se narra el recuerdo de la autora sobre Quintana, enfermero que iba a su casa a suministrar inyecciones. La propuesta genera tensión desde un primer momento ya que aparece la sospecha sobre aquel hombre que daba inyecciones a domicilio "de algo que curaba gripes y resfríos". Para introducir al personaje la autora opta por la 
reproducción del monólogo de Quintana en una oración conectada por comas generando así cierta vertiginosidad y vivacidad al relato:

(...) Quintana hablaba hasta por los codos y era divertido, a ver, boca abajo en la cama, m'hijita, no me llore que no va a sentir nada, cuando pincha Quintana no duele y sí sana, mirá si yo voy a hacerte mal, así quietita querida, no ves que no te dolió y ya está, pinchó Quintana, pinchó, y ahora a otra cosa, chau, que se va Quintana. (Molloy, 2003, p. 13)

Sin explicaciones o descripciones la autora logra en pocas líneas situarnos en la escena. A partir de la elipsis, casi imprescindible en las instantáneas debido a la brevedad y la potencia del texto- nos mostrará, desde el focalizador de la niña, una situación de abuso. Así, las ocho instantáneas reunidas en la serie "Familia" conforman cuadros que tomados en su totalidad construyen la autobiografía de la autora. Paula Sibilia analiza diferentes escritos autobiográficos y reflexiona que tanto las palabras de Ana Frank o Virginia Woolf como las imágenes de Nan Goldin "tejen el minucioso relato autobiográfico cotidiano [que] parecen exudar un poder mágico: no sólo testimonian, sino que también organizan e incluso conceden realidad a la propia experiencia. Estas narrativas tejen la vida del yo y, de alguna manera, la realizan" (Sibilia, 2008, p. 40). Así como conocemos a otros personas a través de compartir un álbum de fotografías -que siempre refieren a momentos muchas veces recordados por aquel que se encarga de enseñárnoslas- o a partir de mirar las fotos publicadas en los diferentes perfiles y/o muros de las redes sociales, la serie de instantáneas autobiográficas construye un yo: narrador, personaje y autor que, teniendo en cuenta la fugacidad del tiempo, nos narra una vida en imágenes.

En los tiempos que corren, ¿sería posible leer o escribir una obra autobiográfica extensa, detallada, a la manera de En busca del tiempo perdido de Marcel Proust? Lo fugaz y lo visual surcan nuestros caminos literarios. Las imágenes que decidimos compartir diariamente nos conforman. Y las series de instantáneas autobiográficas construyen escritos que miran el contexto histórico y cultural, escuchan la manera en que nos comunicamos y expresan a gritos escenas de la vida cotidiana.

\section{Conclusión}

El análisis de las instantáneas es una propuesta para comprender la narrativa actual. Estos textos aparecen en las redes sociales, en los blogs y hasta en los libros de cuentos de los autores más populares pero es necesario darles un marco teórico, comprender que son algo más que cuentos breves: son una propuesta que lee por un lado, la urgencia con la cual nos comunicamos pero a la vez, nos muestra y exterioriza una forma de ver la realidad.

La selección realizada para este trabajo no intenta ser única ni finita sino deliberada con el objetivo de recorrer las similitudes para establecer una definición de un género que se encuentra en proceso de creación. La lectura de instantáneas en un libro sin imágenes no nos aleja, paradójicamente, de la profusa producción de medios audiovisuales, muy por el contrario, la literatura da respuesta ante una realidad que no puede ser evadida.

Llevamos una vida pulsional, vertiginosa, apurada pero no por eso errada, poco literaria y sin características artísticas. Hoy se lee mucho y de múltiples maneras. Leemos textos que nos dejan con la boca abierta, que pasan como ráfagas de viento, nublan la vista y nos dejan otro sabor. Así son las instantáneas. Ni la fugacidad 
de la percepción actual del tiempo, ni la relevancia del soporte audiovisual, ni las redes sociales o los contactos más esporádicos entre personas amedrentaron la riqueza literaria. Muy por el contrario, la han enriquecido.

\section{Notas}

1. Wattpad es una plataforma utilizada mayoritariamente por jóvenes. Los usuarios son de diferentes partes del mundo y se reúnen allí para leer y publicar los textos que ellos producen. Cada usuario conforma su lista de lecturas, realiza votaciones, comentarios y sigue a escritores que no son los consagrados para el mundo editorial pero sí lo son en esta red social. Allí las escrituras se van subiendo a medida que el escritor las redacta y sus seguidores reclaman su continuación y esperan las notificaciones de cualquier comentario o nuevo capítulo (Sorrentino, 2016). Ver https://www.wattpad.com/

\section{Bibliografía}

Almada, S. (2015). El desapego es una manera de querernos. Buenos Aires: Literatura Ramdom House.

Benjamin, W. ([1936] 2008). "El narrador" Introducción, traducción, notas e índices de Pablo Oyarzún R. Santiago de Chile, Ediciones Metales Pesados. Disponible en: http:// www.catedras.fsoc.uba.ar/reale/benjamin_narrador.PDF

Cassany, D. (2000). "De lo analógico a lo digital. El futuro de la enseñanza de la composición”. Lectura y vida. Revista latinoamericana de lectura. $\mathrm{N}^{\circ} 4$, Año 21. Junio. Disponible en: http://www.lecturayvida.fahce.unlp.edu.ar/numeros/a21n4/21_04_Cassany.pdf

Chartier, A. M. (2009). “(Enseñar a) leer y escribir en el presente y a futuro”. Entrevista realizada por Britto, A. y Finocchio, S. Revista propuesta educativa. $N^{\circ} 32$. Disponible en:

http://www. propuestaeducativa. flacso.org. ar/entrevista. php?num=32\&id=0

Cortázar, J. (1970). "Algunos aspectos del cuento" en Diez años de la revista "Casa de las Américas" n 60, La Habana, Julio.

Enriquez, M. (2016). Las cosas que perdimos en el fuego. Buenos Aires: Anagrama.

Ernaux, A. (2015). Diario de Afuera/La vida exterior. Buenos Aires: Milena Caserola.

Genette, G. (1989). Palimpsestos. La literatura en segundo grado. Trad. De Fernández Prieto. Madrid: Taurus, Alfaguara.

Molloy, S. (2003). Varia Imaginación. Buenos Aires: Beatriz Viterbo.

Sibilia, P. (2013). La intimidad como espectáculo. Buenos Aires: Fondo de Cultura Económica.

Sorrentino, F. (2016). “Jóvenes descubridores y creadores: Wattpad y sus 'Stories you'll love”' (ponencia). V Simposio de literatura infantil y juvenil en el Mercosur. Ce.Pro.Pa.LIJ., FACE-Universidad Nacional del Comahue. Cipolletti, Río Negro, 26, 27 y 28 de mayo. 
Abstract: The current perception of the fleetingness of time affects the ways of reading and writing, the way we communicate and the circulation of information. In this context, literature and, specifically, the writing of snapshots make up a contemporary genre that has as its proposal the impact through words. These writings establish a dialogue with photography as they reproduce a moment that, as artistic works, exhibit images (in words) giving multiplicity of meanings. In the following essay we will recognize some of the characteristics of this new genre from the analysis of different works of Argentine authors like Silvia Molloy, Mariana Enriquez and Selva Almada.

Key words: Snapshots - literature - virtuality - reading - writing.

Resumo: A percepção atual da transitoriedade do tempo afeta as formas de leitura e escrita, a forma como nos comunicamos e o fluxo das informações. Neste contexto, a literatura e, especificamente, a escrita de instantâneos forma um gênero contemporâneo cuja proposta é um impacto através das palavras. Essas escritas estabelecem um diálogo com a fotografia, pois, como obras artísticas, exibem um momento visual que permite a multiplicidade de sentidos. No ensaio seguinte, reconheceremos algumas das características deste novo gênero a partir do análise do trabalho de diferentes autores argentinos, como Silvia Molloy, Mariana Enriquez e Selva Almada.

Palavras chave: Instantâneos - literatura - virtualidade - leitura - escrita.

[Las traducciones de los abstracts al inglés y portugués fueron supervisadas por el autor de cada artículo]

Instantáneas: la lectura en los tiempos que corren fue publicado de la página 59 a página70 en Cuadernos del Centro de Estudios de Diseño y Comunicación N72 